\title{
Reducing Aggressive Children's Hostile Attributions: A Cognitive Bias Modification Procedure
}

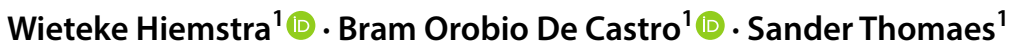

Published online: 3 September 2018

(c) The Author(s) 2018

\begin{abstract}
Children with aggression problems tend to interpret other's intentions as hostile in ambiguous social situations. Among clinically referred children with aggressive behavior problems, this hostile attribution style may be relatively rigid and difficult to change, due to prevalent histories of aversive social experience and/or personal vulnerability. The present study examined the effectiveness of a cognitive bias modification (CBM) training to reduce hostile interpretations of facial expressions in clinically referred aggressive boys. We conducted two experiments: Both Study $1(N=59$, Mage $=11.8)$ and Study $2(N=75$, Mage $=11.5$ ) showed that the training effectively reduced hostile interpretation of facial expressions. However, we found no generalization to relevant other outcomes, including state anger and aggression (assessed using a multi-method approach), and hostile attribution assessed in a game context. Taken together, this research illustrates the potential of employing the CBM procedure to reduce aggressive boys' hostile attributions: The procedure is time and cost-efficient, and relatively easily implemented. Despite this potential, the context-dependency and generalization of effects should be better understood before the procedure can be taken to scale in clinical populations.
\end{abstract}

Keywords Aggression · Hostile attribution - Social information processing $\cdot$ Cognitive bias modification · Psychopathology $\cdot$ Intervention

Aggressive children tend to over-attribute hostile intentions to others, primarily in ambiguous social situations (De Castro et al. 2002; Dodge et al. 2015; Nasby et al. 1980). Interventions that focus on changing these hostile attributions exist (e.g. Guerra and Slaby 1990; Hudley and Graham 1993; Lochman and Wells 2002; Sukhodolsky et al. 2016) but only show modest effects. One reason may be that the interventions mainly target conscious social processing skills for change, such as by using role play and re-training of intentionality. However, making hostile attributions is a relatively implicit process (Wilkoswki and Robinson 2008). Moreover, many children with aggression problems may not be particularly motivated to change attributions that provide them a defense-mechanism that they have often relied on in the past. Accordingly, recent approaches have sought to modify this implicit process by directly influencing the target cognitive bias (i.e., cognitive bias modification (CBM); e.g.

Wieteke Hiemstra

w.hiemstra@uu.nl

1 Department of Psychology, Utrecht University, P.O. Box 80.140, 3508 TC Utrecht, The Netherlands
Hertel and Mathews 2011; MacLeod et al. 2009; MacLeod and Mathews 2012).

CBM constitutes of repeated practice on a specific task that is designed to slightly change attitudes and bias in information processing (MacLeod et al. 2009). CBM does not require conscious reports of personal beliefs or attitudes and therefore does not depend on self-insight. Some studies using CBM to target hostile attributions, conducted in populationbased and at-risk samples of children and adults, have shown promising results (Penton-Voak et al. 2013, 2017; Stoddard et al. 2016; Vassilopoulos et al. 2015). However, CBM has not yet been tested yet in those who are in particular need of intervention to prevent adverse outcomes: clinically referred children with aggressive behavior problems (e.g. De Castro et al. 2002; Fergusson et al. 2005). Although it is possible that results obtained in population-based or at-risk samples will generalize to these children, this cannot be simply assumed. Among clinically referred children with aggressive behavior problems, hostile schemata may be relatively rigid and more difficult to change due to prevalent histories of aversive social experiences or personal vulnerabilities (e.g., low IQ, difficult temperament, or impulsivity; Dodge 2006). The present study 
therefore tested the effectiveness of a CBM training to target hostile attributions in clinically-referred children with aggressive behavior problems.

\section{Hostile Attributions}

Children with aggression problems differ in their social information processing (SIP) from less aggressive peers: They have an automatic tendency to interpret ambiguous social cues as hostile, known as "hostile attribution bias" (Crick and Dodge 1994; De Castro et al. 2002; Dodge et al. 2015; Nasby et al. 1980), which is especially apparent in their interpretation of social cues (Crick and Dodge 1996; Dishion et al. 1995; Dodge 2006). Hostile attribution bias seems to be a trans-diagnostic driver of aggression (e.g., Henry et al. 2015).

People use heuristics (i.e., representativeness and availability heuristics) to interpret information, which may lead SIP to become more rigid over time. For example, if children have experienced hostility in the past, this often becomes readily available information in their schemata, and will influence them to make hostile interpretations again in the future (Dodge 2006). These hostile interpretations instigate more aggression, which might in turn provoke others to respond with hostility as well, thereby triggering a negative recursive cycle.

One factor that is particularly important in the interpretation of social cues, is the perception of others' facial expressions of emotion (Ekman 1993; Etcoff and Magee 1992; Hendriks and Vingerhoets 2006). Facial expressions of emotion have a key function in regulating social interaction between humans and can convey signs of intent (Walker-Andrews 1997). Therefore, facial expressions are an important basis of hostile attributions. Ambiguous facial expressions are interpreted more negatively by aggressive individuals than by others (Fairchild et al. 2009; Mellentin et al. 2015; Schönenberg and Justyte 2014), which may contribute to the development and maintenance of aggression (Crick and Dodge 1994; Dodge 2006). This phenomenon provides an entry point for intervention: To the extent that we may be able to help aggressive children perceive ambiguous facial expressions in less hostile ways, we may reduce their hostile attribution bias and associated behavior problems. There is now growing evidence that supports a causal role of biased facial expression recognition in conduct problems (Penton-Voak et al. 2017).

\section{Intervening with Hostile Attributions}

Most present-day interventions that target hostile attributions in children and adolescents use explicit techniques such as re-training intention attribution or behavioral responses to cues (i.e. through role play; Guerra and Slaby 1990; Hudley and Graham 1993; Lochman and Wells 2002). These interventions often lead to modest behavior changes, in both clinical and non-clinical samples, which illustrates that hostile attributions can be altered, and may function as a mediator for behavioral change.

One limitation of these intervention procedures, however, is that they typically rely on explicit cognitive behavioral training that requires reflection, while hostile attributions are implicit processes (Wilkoswki and Robinson 2008). Such explicit training may attempt to help children suppress automatic social information processing, and replace it with a non-stereotype response. However, conscious change of an automatic process is hard to achieve and potentially inefficient (Monteith et al. 1998). For children with aggression problems, who tend to be impulsive, high in emotionality, somewhat less (verbally) intelligent, and low on effortful control, this might be especially problematic (De Castro et al. 2002; Eisenberg et al. 2005). Furthermore, these children may often lack motivation to change patterns of cognition that offer them a defense-mechanism.

To circumvent these problems, it may be promising to directly influence hostile attributions by targeting the automatic process that gives rise to them. By targeting such an automatic process, and not letting children be conscious of the cognitions they are expected to change, we are less dependent on children's ability and motivation to change. Implicit interventions in modifying attributional styles have already proven to be effective in other domains of psychopathology, especially anxiety. A meta-analysis showed that CBM experimental paradigms can reduce maladaptive biases and associated anxiety symptoms in healthy undergraduates and adults (Hallion and Ruscio 2011).

Recently, studies have adapted CBM to target hostile attributions and associated aggressive behavior. One study in 10-12 year olds that used vignettes to assess hostile versus benign responding to provocation found reductions in hostile attributions and self-reported aggression following CBM (Vassilopoulos et al. 2015). However, this study did not use a control-group, and so causality could not be established. Penton-Voak et al. (2013) conducted CBM experiments with healthy adults and high-risk adolescents in residential care. They successfully reduced the extent to which participants perceived anger in ambiguous facial expressions, which led to reductions in hostile attributions and self- and staffreported aggressive behavior in both groups. However, none of this work included clinically referred children. In the present study we sought to begin to fill this gap, and examined effects of a CBM procedure on hostile attributions in clinically referred children with aggressive behavior problems.

A recent meta-analysis and review, which both focused on mental health outcomes other than hostile attributions, suggested that CBM interventions typically are (moderately) 
effective to reduce cognitive bias, but less so to change behavioral outcomes (Cristea et al. 2015; Krebs et al. 2017). Although this work primarily focused on anxiety and depression outcomes, it begs the question of how readily potential effects on hostile attribution bias will generalize to reducing aggression, especially in clinically referred children. The aggressive predispositions of these children tend to be robust, particularly when they grow up in social environments that are harsh, reinforcing their hostile attributions (e.g. Nix et al. 1999).

\section{Aim of the Present Research}

The aim of the present research was to systematically test whether an implicit bias modification training (PentonVoak et al. 2013) reduces hostile interpretation of facial expressions in clinically aggressive boys. To this end, we conducted two experiments. We only studied boys, because boys show more direct aggression, which is key to disruptive externalizing problems (Card et al. 2008). We focused on children in late childhood and early adolescence, an age period when hostile attributions tend to have a pronounced impact on child problem behavior (De Castro et al. 2002).

Aggression is a heterogeneous phenomenon, with various manifestations (i.e., forms) and various underlying intentions (i.e., functions; Polman et al. 2009). Concerning functions, a distinction can be made between "reactive" and "proactive" aggression. Reactive aggression is a reaction to a perceived threat, whereas proactive aggression is planned, relatively unemotional behavior (Polman et al. 2007). Hostile attribution is a key determinant of, specifically, reactive aggression (e.g. Crick and Dodge 1996; De Castro et al. 2002; Dodge et al. 1990). We hypothesized that boys prone to aggression with reactive function would benefit most from our training (i.e., we hypothesized that reactive function of aggression would moderate the effects of the training on interpretation in Studies 1 and 2).

We additionally explored whether the putative effects of the training on hostile interpretation would generalize to aggressive behavior (Studies 1 and 2). Previous work found that modification of bias in emotional processing also has effects on mood (Penton-Voak et al. 2013), and so we investigated whether our training would reduce state anger (Study 2). As such, we explored the therapeutic potential of direct bias modification (MacLeod and Mathews 2012). Given that severe aggression problems are multi-determined, we did not expect our focused training to exert effects of similar magnitude as more standard, comprehensive interventions that target multiple determinants. Rather, we sought to explore whether targeting a single maladaptive process (i.e., hostile interpretation of facial expressions as a measure of hostile attribution in general) would lead to observable reductions in aggression.

\section{Study 1}

We conducted an experiment, following procedures developed by Penton-Voak et al. (2013), in a sample of clinically-referred boys with aggressive behavior problems. The primary goal was to investigate whether the training would reduce hostile interpretation and whether this effect would be moderated by reactive function of aggression; a secondary goal was to explore whether aggressive behavior would decrease accordingly.

\section{Methods}

\section{Participants}

The sample consisted of 59 boys aged 9-14, with a mean age of 11 years and 8 months. They were recruited from four schools providing special elementary education for children with behavior problems. In the Netherlands, about $2.5 \%$ of the school-aged population is referred to this type of school (Statistics Netherlands 2014). Criteria for referral include: (1) Children have at least one DSM-diagnosis, (2) the severity of children's behavior problems falls within a clinical range and prohibits participation in regular education, and (3) children are treated for their problems in a clinical setting. A multidisciplinary examination committee decides on placement in this type of school. Education is provided in small classes (of about 10 children), by specialized teachers trained to provide individualized supervision and guidance.

The participating schools are situated in rural and suburban areas in the middle and south of the Netherlands, although boys came from across the country. The initial sample consisted of 78 participants, but 19 of them dropped out of the study, either because they were absent from school on training days (e.g., due to illness, or therapy-related absence) or because teachers failed to complete both aggression measures. Children who dropped out of the study did not differ from those in the final sample in terms of their baseline hostile interpretation (if available; $F(1,74)=.33, p=.568$ ).

\section{Measures}

\section{Instrument for Reactive and Proactive Aggression}

Boys' aggressive behavior was measured using the Instrument for Reactive and Proactive Aggression (IRPA; Polman et al. 2009). This is a teacher-report instrument that assesses forms and functions of aggression separately. The IRPA 
contains eight form items (e.g. "How often did the child hit someone in the past week?"), and seven function items (e.g. "How often did he do this because he was angry?"). Ratings are given on a Likert scale ranging from 0 (never) to 4 (multiple times a day) for form, and from 0 (never) to 4 (always) for function. We created a total sum score for aggression, and a separate sum score for reactive function. We slightly deviated from the original IRPA format and chose not to distinguish functions for each form separately, yielding a briefer measure. Good discriminant, convergent, and construct validity have been reported for the IRPA (Polman et al. 2009). Alpha's in the current sample were all acceptable to good $(\alpha$ total $=.92, \alpha$ proactive aggression $=.83$, and $\alpha$ reactive aggression $=.73$; Cohen 1988).

\section{Tally Form}

To obtain an objective aggression measure, teachers also completed an aggression tally form. Teachers tallied each occurrence of three form scales of aggression during a school day at pre-test and at post-test, including eight items for (a) physical aggression (i.e., hitting, kicking, pushing), (b) verbal aggression (i.e., name calling, arguing, threatening), and (c) covert aggression (i.e., doing sneaky things, refusing to do something). For each of these behaviors, teachers also tallied which function the aggressive act served. A sum score was made to see how many times a child behaved reactively aggressive. Since we designed this tally list for this study, no information on validity or reliability is available.

\section{Emotional State}

State anger and state positive mood were measured every day right before the training by asking participants to indicate "how you feel right now" on an "anger thermometer" and a "happiness thermometer" (e.g. Elias 2004). Responses ranged from 0 ("not at all angry") to 3 ("very angry"). We used the anger thermometer in the preliminary analyses to see whether boys' state anger influenced their interpretation on the task.

\section{Computer Training}

Following Penton-Voak et al. (2013), we created a computerbased training for this study using the software package OpenSesame (Mathôt et al. 2012). We made photos of nine boys ages $10-15$, recruited in an acting class at a secondary school in the Netherlands. Informed consent to make and use the photographs was obtained from the boys themselves and their parents. The boys were photographed while asked to look either happy or angry. The happy and angry images were used as endpoints to generate nine linear morph

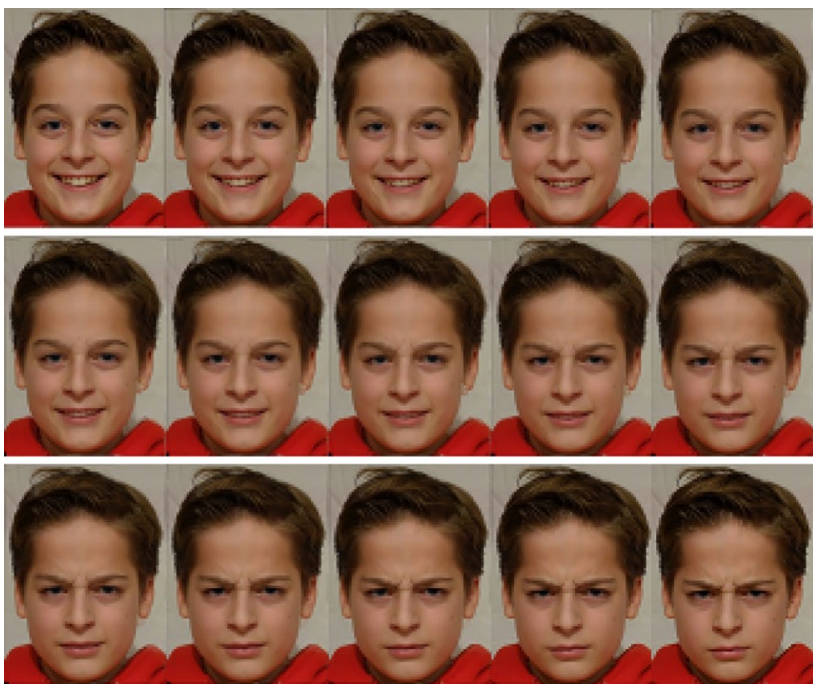

Fig. 1 Example of one of the morphing continua: unambiguously happy, ambiguous, and unambiguously angry (from left to right, top to bottom, respectively)

sequences consisting of 15 images that gradually transition from happy to angry, with emotionally ambiguous images in the middle (see Fig. 1 for an example). These morph sequences were used as experimental stimuli in the training. Three versions of the computer task were created with a different order of the nine morphing sequences. This was done to be sure that any effects of the training did not depend on a specific morphing sequence. Participants receiving the three different versions did not differ significantly on their first measurement of interpretation (balance point; $F(2$, 56) $=0.15, p=.860$ )

Images were presented for $500 \mathrm{~ms}$ (Vlamings et al. 2010), preceded by a fixation cross. The pictures within the morphing sequences were presented in random order for every participant. Stimulus presentation was followed by a prompt asking participants to respond to a two-alternative forcedchoice judgment whether the morphed image they saw was happy or angry. Responses to such morphed images tend to shift categorically (either happy or angry) from one response to the other across the sequence (Etcoff and Magee 1992; Young et al. 1997). This shift enabled us to obtain an estimation of the balance point at which the child was equally likely to decide on happy or angry in the presented morph. This was done by calculating the number of 'angry' responses as a proportion of the total number of trials. The balance point was used as a measure of interpretation.

The training took place on five consecutive (school) days. Each day, we first established a balance point in a baseline phase (using 45 trials on day 1 [ $=3$ complete morph continua], and 30 trials on the subsequent days $[=2$ complete morph continua]), after which we offered training (using 60 trials each day). On day 5 we also offered a new baseline 
phase, to establish the "final" balance point for each participant. The first balance point and the last balance point were calculated based on the same morph continua.

During the training phase, participants were provided computer-generated feedback on the responses they gave, based on their personal balance points that we established that day. The feedback that participants received on each response they gave was either "correct" (i.e., if they identified images two morph steps above their balance point image as "happy" or faces above that image as "angry") or "incorrect" (in all other cases). The feedback was displayed visually on screen for $1 \mathrm{~s}$. The exact feedback message read: "Correct/incorrect! That face was happy/angry". To illustrate, suppose that a child's balance point was at the seventh morph along the sequence. In the training condition, the child then received "correct" feedback only if he gave a "happy" response for all morphs up until the ninth morph along the sequence. In the control condition, no feedback was given. Overall, the boys were encouraged to finish the task and pay attention during the task (i.e., which took about 5-10 min each day). When children's attention appeared to drift, the experimenter helped them focus on the task again, or offered to have a short break.

\section{Procedure}

We obtained ethics approval from our local ethics review board. Next, twelve schools for special education for children with aggressive behavior problems across the Netherlands were requested to take part in the study, and five chose to do so. The schools distributed consent letters to parents/caregivers - only boys who received active parental/caregiver consent were allowed to take part in the study (consent rate was approximately 75\%). Participants were randomly assigned to the experimental or control conditions. Teachers and schools were blind to conditions.

On each of the 5 days of training, boys completed the mood thermometers prior to the computer task. If a boy appeared agitated, we let him return to the classroom and try again later that day (this occurred 11 times). After the training, boys could play a fun computer game for a maximum of $5 \mathrm{~min}$ if they wanted to, to heighten their motivation to take part in the study. Boys also received a small present (a pen or eraser) at the third and the fifth day to thank them for their participation. To establish treatment fidelity, we kept a log and recorded any incidents where boys were 'not focusing on the task'/'just pushing the same button repeatedly' (this occurred about five times).

Teachers completed the tally list and the IRPA the week before and the week after the boys received the training. The tally list was completed every day during these weeks; the IRPA was completed once at the end of the week.

\section{Missing Values and Data Reduction}

Prior to data analysis, we checked treatment fidelity. We considered boys' data to be missing if they had two or more 'unrealistic' values. 'Unrealistic' values were opposite scores on the extreme morphs in the task (i.e. boys choosing "angry" for the two most happy pictures, and vice versa; this occurred for $1.7 \%$ of all balance point measures). Missing values were handled as follows: If the first and/or the last balance point missed, this value was replaced with the balance point from the previous day (and with the day 2 balance point for day 1; this was the case for 3.4\%). For the tally list, any missing values were replaced with the mean of aggressive behaviors from the other days (this was the case for 3\%). Some teachers did not return their reports for the second assessment, and so in the analyses of effects on aggression we left out the data from 11 boys who were in the initial sample. These boys did not significantly differ from the boys included in the aggression analyses on pretest hostile interpretation, aggression, or reactive function of aggression. Because the tally list and the IRPA were highly correlated $(r=.87, p<.001)$, we chose to aggregate these measures. Because reactive function of aggressive behavior was based on the aggression measures (IRPA and tally list), the two sum scores of reactive aggression were also aggregated $(r=.51, p<.001)$.

\section{Results}

\section{Preliminary Analyses}

We present descriptive statistics in Table 1. The distribution of the aggregated aggression score (z-scores) was slightly skewed; teachers reported low levels of aggression scores for about $25 \%$ of the participants. However, mean levels of aggression were still significantly higher than mean levels reported in studies using the IRPA in a general population sample $(t(57)=5.20, p<.001 ; M=0.83$ in this study, compared to $M=0.25$ in Polman et al. 2007). State-anger, as measured by the anger thermometer, was not significantly associated with interpretation of the facial expressions at baseline $(r=.14, p=.317)$.

\section{Main Analyses}

We used multiple regression analysis to test the effect of the training on hostile interpretation. Hostile interpretation, defined as the "final" balance point, served as the dependent variable (see Table 2 for the complete model). The training significantly decreased hostile interpretation $(F(4,54)=23.12$, $p<.001)$. Figure 2 presents differences in balance points (i.e., hostile interpretation) between conditions. Participants in the 
Table 1 Descriptive values of all main variables used in analyses split by condition (study $1 ; \mathrm{N}=59, \mathrm{HI}=$ hostile interpretation)

\begin{tabular}{|c|c|c|c|c|}
\hline \multirow[t]{2}{*}{ Variables } & \multicolumn{2}{|c|}{ Experimental group } & \multicolumn{2}{|l|}{ Control group } \\
\hline & $\bar{M}$ & Range & $\bar{M}$ & Range \\
\hline Age & $\begin{array}{l}11 \text { years } \\
8 \text { months }\end{array}$ & $\begin{array}{l}9 \text { years } 5 \text { months } \\
\text { to } 13 \text { years } \\
10 \text { months }\end{array}$ & $\begin{array}{l}11 \text { years } \\
10 \text { months }\end{array}$ & $\begin{array}{l}9 \text { years } 2 \text { months } \\
\text { to } 14 \text { years } \\
1 \text { months }\end{array}$ \\
\hline Pre-test hostile interpretation & .50 & $.29-.69$ & .48 & $.24-.71$ \\
\hline Pre-test state anger & 1.42 & $1.00-4.00$ & 1.36 & $1.00-3.00$ \\
\hline Pre-test aggression (z-score) & .08 & -.98 to 3.04 & .01 & -.98 to 3.02 \\
\hline Pre-test reactive aggression (z-score) & -.14 & -1.09 to 1.93 & .12 & -1.09 to 2.42 \\
\hline Post-test hostile interpretation & .29 & $.13-.47$ & .52 & $.27-.73$ \\
\hline Post-test aggression (z-score) & -.31 & -.78 to .73 & -.33 & -.78 to 1.67 \\
\hline
\end{tabular}

Pre-test aggression was indexed by teacher' reports on aggressive behaviors in 1 week
Table 2 Summary of regression analysis for variables predicting "post-test hostile interpretation" (Study 1; N=59)

\begin{tabular}{lllll}
\hline & $\mathrm{R}^{2}$ & $\mathrm{~B}$ & $\mathrm{SE} \mathrm{B}$ & $\beta$ \\
\hline Final model & $.63^{* *}$ & & & \\
Pre-test hostile interpretation & & .46 & .14 & $.28^{* *}$ \\
Condition & & .11 & .01 & $.70^{* *}$ \\
Reactive aggression & & .03 & .02 & .16 \\
Condition $\times$ reactive agg & & .03 & .02 & .14 \\
\hline
\end{tabular}

$* p<.05 ; * * p<.01$

experimental condition showed a shift in balance point of approximately .20 (on a $0-1$ scale) relative to participants in the control condition. On average, boys in the experimental condition rated 8 morphs along the sequence as angry at baseline, while they did so for only five morphs after the training. Thus, boys in the experimental condition shifted from a hostile bias to an unbiased interpretation.

Next, we analyzed whether the boys' reactive function of aggression moderated the condition effect. For this question, reactive aggression and its interaction with condition (based on centered variables) were added to the model. Neither reactive aggression, nor the interaction significantly predicted change in hostile interpretation.

Next, we conducted another regression analysis to test the effects of the manipulation on aggressive behavior. Aggressive behavior at post-test served as the dependent variable. No significant effects emerged $(\beta=-.01, S E=.09, p=.923)$ : both the experimental and the control group decreased significantly in aggression at post-test $(F(1,18)=6.37, p=.021$, and $F(1,26)=10.38, p=.003$, respectively).

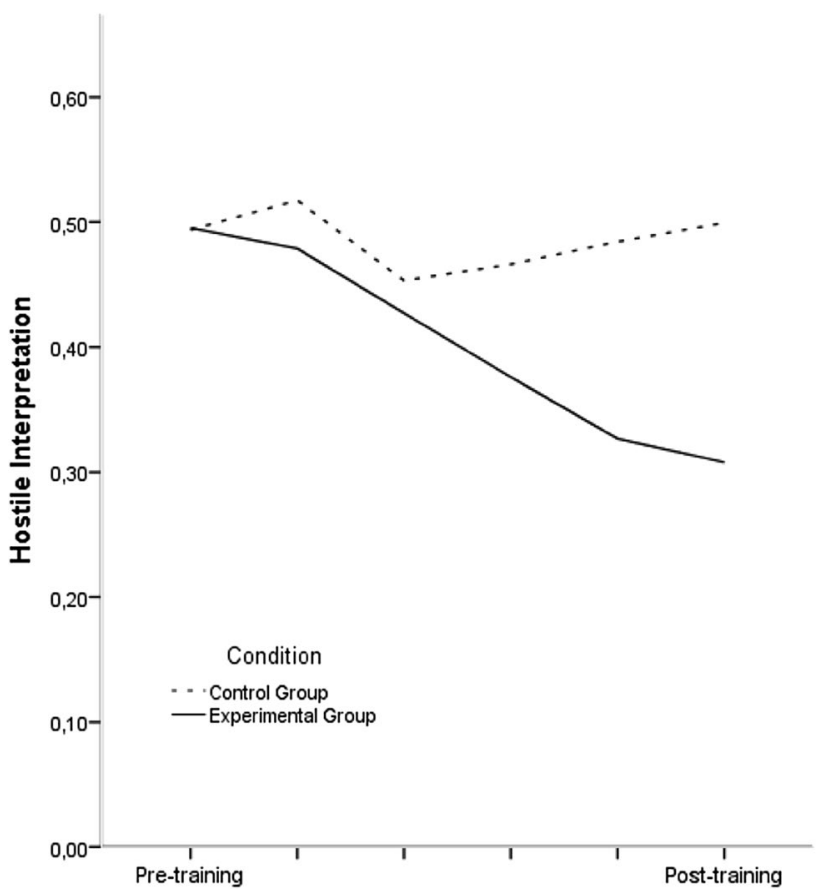

Fig. 2 Effect of the on the boys' hostile interpretation for the five consecutive days (last day includes two measurements)

\section{Discussion}

In Study 1, we investigated whether a CBM training could reduce referred boys' hostile interpretation. Boys in the experimental condition showed a shift in interpretation compared to boys in the control condition. This is a promising finding, especially because altering hostile attributions in children with disruptive behavior problems can be notoriously difficult (Dodge 2006). However, as reported by teachers, the training did not impact aggressive behavior, nor did we find any moderating effect of boys' reactive aggressive predispositions. 
We considered the possibility that a lack of effect on aggression was due, in part, to the aggression measure we used. Teacher reports of aggression, although valuable, can only provide information on aggressive behavior in the schoolcontext. Therefore, we chose to conduct another experiment to investigate possible effects on an alternative aggression measure. We also investigated the emotional impetus to (reactive) aggression: feelings of anger. Anger can drive the link between situational variables and aggression (Anderson and Bushman 2002). Since we target a situational variable (interpretation of faces), and explore effectiveness on aggression, it is relevant to explore effects for anger. Accordingly, Penton-Voak et al. (2013) tested an effect of their training on anger (along with aggression) as well.

\section{Study 2}

We conducted Study 2 to replicate our finding that the training reduces aggressive boys' hostile interpretation. We used a shorter training procedure, given that in Study 1 we found the biggest shift in interpretation after day three. Furthermore, Study 2 investigated the effect of the training on both anger and an alternative measure of aggression.

\section{Methods}

\section{Participants}

The sample consisted of 75 boys ages $8-13$, with a mean age of 11 years and 5 months. They were recruited from five schools providing special elementary education for children with behavior problems. Participating schools are situated in rural and suburban areas in the centre and south of the Netherlands, but boys came from across the country. The initial sample consisted of 87 participants; 12 boys dropped out of the study, because they failed to complete the training (e.g., due to illness, or therapy-related absence from school). Participants were diagnosed with a DSM-IV disorder by multidisciplinary teams of professionals (obtained from school care records; 34.6\% Autism Spectrum Disorder (ASD), 12.8\% Attention-Deficit Hyperactivity Disorder (ADHD), $21.8 \%$ both ADHD and ASD, 11.5\% Oppositional Defiant Disorder (ODD)/Conduct Disorder (CD), 6.4\% both ADHD and ODD, $12.9 \%$ other/unknown diagnosis).

\section{Measures}

\section{Computerized Training}

We used the same stimuli as in Study 1, but implemented the training as an app installed on an I-pad. Again, three versions of the training were created with a different order of the nine morphing sequences. This was done to validate the pictures and be sure that any effects of the training did not depend on a specific morphing sequence. Participants receiving the three different versions did not differ significantly on their first measurement of interpretation (balance point; $F(2,72)=0.58, p=.562)$.

Testing took place during three consecutive days. The session at the first two days consisted of two phases: a baseline phase and a training phase. The last day consisted of three phases: a baseline, training, and new baseline phase.

\section{State Anger Questionnaire}

To measure state anger we used the State Anger subscale of the State-Trait Anger Expression Inventory for Children and Adolescents (STAXI-CA; del Barrio et al. 2004). This measure was derived from the original adult version (STAXI; Spielberger 1988), and shows acceptable psychometric properties for use in children. The State Anger subscale consists of 12 statements regarding state anger, such as "At this moment, I feel like hitting someone". The items can be rated along a scale from 0 ("not at all true") to 3 ("completely true"). Cronbach's alpha was good in our sample ( $\alpha=.95$; Cohen 1988).

\section{Aggression Measure}

To assess aggression we used another, self-created app based on the 'Survivor' procedure that has been used in previous research (e.g., Reijntjes et al. 2010). The procedure lets participants create a 'profile page' on which they get feedback from (imaginary) other boys. First, a photo was taken that was shown on participants' profile page. Next, participants completed some information on their personal page, like their hobbies, occupational goals, and things they like and dislike about themselves. Subsequently, participants received alerts that they other boys gave them feedback. They could see the feedback at the bottom of their profile page, along with a picture of the boy who 'reacted'. By clicking on the feedback, participants could visit the profile pages of these boys, where they could post feedback themselves. Participants could then 'comment' on the reactions they received. All participants received four ambiguous reactions ${ }^{1}$ to their profile, which were "Whuut? He is kind of funny", "Wow...", "Seems like a nice boy, but I don't know if I would want to be friends with him" and "..Sick!". These ambiguous reactions were chosen after consulting existing

\footnotetext{
${ }^{1}$ In the original Survivor game, feedback on participant profiles was manipulated to be positive, neutral or negative. Consistent with the present study purposes - to investigate interpretations of and reactions to ambiguous situations-we designed the feedback in this study to be ambiguous.
} 
profile pages and reactions of children about the same age. The order in which participants received these reactions, and the way photos and profile pages were coupled to these reactions, were presented in random order. Participants' responses ('comments') on these reactions served as the first measure of aggression (frequency of aggressive responses), coded by two independent coders. They coded each reaction is one of four categories $(999=$ missing/unclear, $0=$ nice, $1=$ neutral, 2 = clearly mean/aggressive). Inter-rater reliability for these four coding categories was $\kappa=.825, \kappa=.827$, $\kappa=.887, \kappa=.888$, respectively; almost perfect agreement (Landis and Koch 1977).

In addition, participants were given the opportunity to aggress against the peers who responded to their profile by influencing the amount of money these peers received for participation in the game. The default fee was $€ 2$. Participants could leave this amount unchanged, subtract $€ 1$ or $€ 2$, or add $€ 1$ or $€ 2$.

Next, we asked participants to rate four statements. The statements were "They wanted to be mean to me", "They wanted to say bad things about me", "They put effort in describing me the way I am", and "They tried to be honest and fair in their reactions". Only the first two statements were used as a measure of hostile intent attribution. The participants rated these statements along a scale ranging from 0 (completely not agree) to 4 (completely agree). The two statements $(r=.63, p<.001)$ were averaged to a total mean score of hostile intent attribution.

\section{Procedure}

We again obtained ethics approval from our local ethics review board. Nine schools for special education for children with disruptive behavior problems across the Netherlands were requested to take part in the study, and five chose to do so. The schools distributed consent letters to parents/caregivers —only boys who received active parental/caregiver were allowed to take part in the study (consent rate was approximately $70 \%$ ). Participants were randomly assigned to the experimental or control conditions. Teachers and schools were blind to conditions.

Each participant engaged in three sessions, once a day for three consecutive days in the same school week. On the last day, participants played the 'Survivor game' directly after the training. They completed the state anger questionnaire on the first day (before training) and the last day (after training and 'Survivor'). Again, to establish treatment fidelity, we kept a log and recorded any incidents where boys were "not focusing on the task'/ 'just pushing the same button repeatedly' (this occurred three times).

Participants were thoroughly debriefed. They were told that the peers and the feedback they received were fictitious, and they were informed about the purpose of the study. Research has shown that these debriefing procedures are effective for young adolescents (Hurley and Underwood 2002). Previous versions of the Survivor procedure have been used by us and others and are generally positively evaluated and enjoyed by participants. Participants received a small present (a pen or eraser) at the last day to thank them for their participation.

\section{Missing Values and Data Reduction}

Prior to data analysis, we checked treatment fidelity. As in Study 1, we considered participants' data to be missing if they had two or more 'unrealistic' values (this was the case for $1.6 \%$ of the balance points measured). Missing values were handled as in Study 1. Single missing values on the questionnaire were replaced by the participant mean $(0.2 \%$ single missing values). For the 'Survivor' game, about 33\% of participants responded aggressively at least once. Accordingly, the distribution of this variable was not normal. We thus chose to make this a categorical variable (aggression: yes, at least once/no).

\section{Results}

\section{Main Analyses}

Descriptive statistics for the main variables are presented in Table 3. We used multiple regression analysis to test the effect of the training on hostile interpretation. Hostile interpretation, the "final" balance point, served as the dependent variable. Figure 3 presents differences in balance points between conditions. Again, the training decreased hostile interpretation significantly $(F(2,72)=37.77, p<.001)$. Participants in the experimental condition showed a shift in balance point of .11 (on a $0-1$ scale) relative to participants in the control condition $(\beta=.37, S E=.03, p<.001)$. On average, boys in the experimental condition rated 7.5 morphs along the sequence as angry at baseline, while they did so for only only 6 morphs after the training. Thus, replicating Study 1, the CBM procedure was effective at reducing participants' hostile interpretation of ambiguous facial expressions.

Next, we conducted another regression analysis to test the effects of the manipulation on state anger. We first examined links between hostile interpretation on the training task and reported state anger at baseline. The first balance point and pre-training state anger were significantly negatively correlated, $r=-.34, p=.003$. Thus, higher levels of anger in the boys were associated with more hostile interpretation. In the regression analysis, state anger post-test served as the dependent variable. No significant effects of the training were found for state anger $(\beta=.09$, 
Table 3 Descriptive values of all main variables used in analyses split by condition (study 2; $\mathrm{N}=75$ )

\begin{tabular}{|c|c|c|c|c|}
\hline \multirow[t]{2}{*}{ Variables } & \multicolumn{2}{|c|}{ Experimental group } & \multicolumn{2}{|c|}{ Control group } \\
\hline & M & Range & M & Range \\
\hline Age & $\begin{array}{l}11 \text { years } \\
8 \text { months }\end{array}$ & $\begin{array}{l}8 \text { years } 9 \text { months to } \\
13 \text { years } 7 \text { months }\end{array}$ & $\begin{array}{l}11 \text { years } \\
1 \text { months }\end{array}$ & $\begin{array}{l}8 \text { years } 2 \text { months } \\
\text { to } 13 \text { years } \\
0 \text { months }\end{array}$ \\
\hline Pre-test hostile interpretation & .49 & $.23-.83$ & .50 & $.33-.70$ \\
\hline Pre-test state anger & .36 & $.00-1.92$ & .68 & $.00-3.00$ \\
\hline Post-test hostile interpretation & .41 & $.10-.83$ & .52 & $.20-.83$ \\
\hline Post-test state anger & .21 & $.00-1.92$ & .24 & $.00-1.50$ \\
\hline Post-test aggression (coins) & 2.21 & $.75-3.50$ & 2.16 & $.50-4.00$ \\
\hline Post-test aggression (reaction) & .30 & $.00-1.00$ & .16 & $.00-1.00$ \\
\hline Post-test hostile intent & 1.30 & $.00-4.00$ & 1.55 & $.00-4.00$ \\
\hline
\end{tabular}

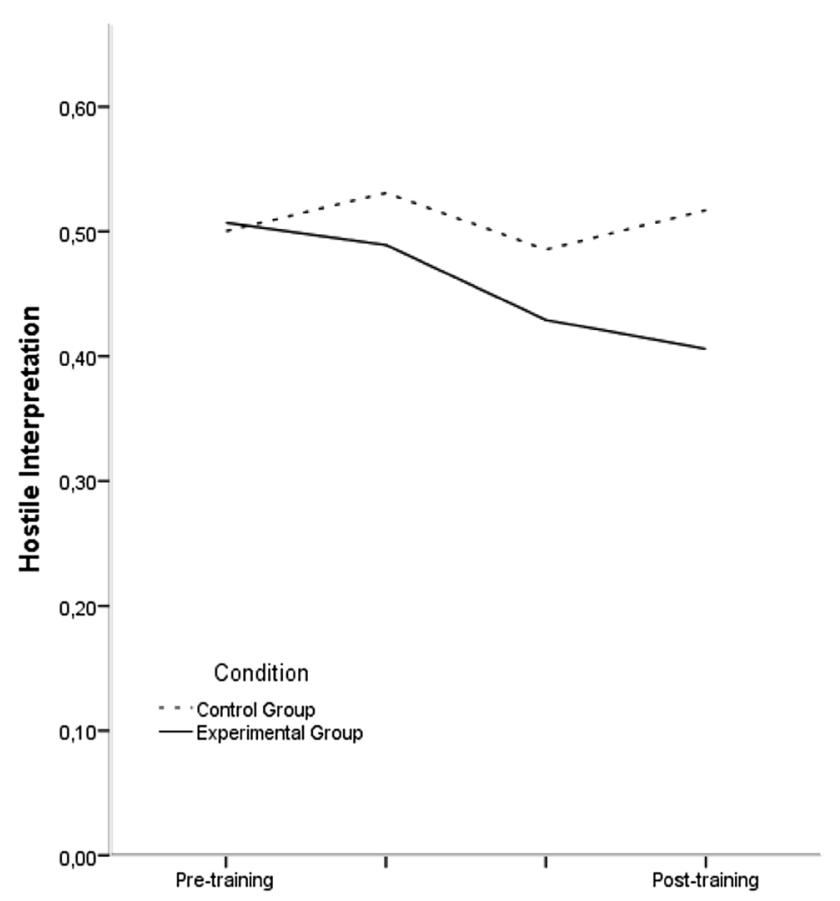

Fig. 3 Effect of the training on the boys' hostile interpretation for the three consecutive days (last day includes two measurements)

$S E=.09, p=.372)$, only pre-test anger was a significant predictor in the model $(F(2,72)=14.17, p<.001)$.

Lastly, we conducted three additional regression analyses to test the effects of the manipulation on the intent attribution- and aggression measures within the 'Survivor' game. The training was not effective in reducing aggression, regardless of whether aggression was indexed by how much money participants took away from their peers $(F(1,73)=0.12, p=.746, \beta=.04, S E=.16)$, or how aggressively they reacted on others' profile pages $\left(\chi^{2}(1\right.$, $N=75)=2.22 p=.136$ ). Also, the training was not effective in reducing hostile intent attribution as indexed by the two relevant statements in 'Survivor,' $(F(1,73)=0.85$, $p=.358, \beta=-.11, S E=.27)$.

\section{Discussion}

In Study 2, we again investigated whether a CBM training could reduce referred boys' hostile interpretation. Boys in the experimental condition showed a shift in interpretation compared to boys in the control condition. Compared to Study 1 , this effect was reached in a smaller time-frame. However, comparable to Study 1, the training did not impact aggressive behavior and hostile intent attribution as measured in a game-context, nor did we find an effect on state-anger.

\section{General Discussion}

We conducted two experiments to investigate whether a CBM training reduces hostile interpretation of facial expressions in clinically aggressive boys. It does. In both studies, boys in the experimental condition showed a benign interpretational shift compared to boys in the control condition. However, we found no generalization to state-anger and aggression, as measured using a multi-method approach, nor to hostile intent attribution in a game context.

Our finding that the training reduces hostile interpretation of facial expression builds on and extends similar findings obtained in other populations (i.e., typically developing children and adults, and high-risk adolescents; Penton-Voak et al. 2013, 2017; Stoddard et al. 2016; Vassilopoulos et al. 2015). The implicit process of hostile attribution is strongly influenced by existing schemata, and may therefore become increasingly rigid over time (Dodge 2006). However, our two experiments show that aggressive children's predisposition to make hostile interpretations can be changed using a time-efficient procedure, with little burden for children 
taking part. As such, CBM may be a promising means to help break the cycle of hostility that aggressive children often face.

We found no generalization from curbed hostile interpretation of facial expressions to self-reported state anger (Study 2) and aggressive behavior (regardless of whether it was assessed by teacher-reports or behaviorally). This is at odds with previous work, which did find such generalization (Penton-Voak et al. 2013; Vassilopoulos et al. 2015). That said, our findings do dovetail with the outcomes of a recent meta-analysis, which found that in other mental health domains (especially anxiety; Cristea et al. 2015), generalization of CBM effects to behavioral outcomes is rare.

Several factors may explain why we did not find an effect on aggressive behavior. One possibility is that CBM has a genuine effect on the specific bias that we targeted (i.e., children's hostile attributions of facial expressions), but somehow this effect fails to transpire to other contexts (e.g., hostile attributions in the game task), and to related emotional- and behavioral responses. Perhaps CBM does not sufficiently target the constellation of cognitive factors underlying severe aggression problems, to be able to prevent aggressive behaviors. Indeed, other social information processes, such as cognitive and regulatory control, may be important to reduce aggression as well (e.g., Salemink and Wiers 2011; Wilkowski et al. 2015). Furthermore, aggressive children may often suffer from recursive, relatively ingrained interpersonal problems; to really break the vicious cycles that maintain their aggression problems, additional intervention targeting children's immediate social environment may be necessary (e.g. classroom intervention, parent training). Another possibility is that children did not truly change their attribution style, even if they learned how to interpret facial expressions as less angry. We intended to teach participants that ambiguous expressions are not as hostile as they may think, but we cannot rule out the possibility that participants learned from the procedure that people may not show angry facial expressions even if they actually are angry and hostile inside. Finally, we can not rule out the possibility that children knew what was expected from them in the task and behaved accordingly, without internalizing a shift in interpretation style. However, our training was designed in a way that children where not reinforced for giving the same answer ('happy') all the time, as answers too far away from their balance point were not considered correct. Even if children would give the same answer ('happy') all the time, this could not affect the findings, since these children were excluded from the training. Moreover, this explanation would also not be able to account for earlier findings (e.g., Penton-Voak et al. 2013).

Another limitation concerns the nature of our samples. All participants were clinically referred for aggressive behavior problems, but we did not include structured diagnostic interviews, nor do we have information on possible medication use. Although we assume that hostile intent attribution is a trans-diagnostic driver of aggression, future research is needed to establish whether CBM procedures exert similar effects for children with different diagnoses (e.g., children with an autism spectrum disorder vs. those with an oppositional defiant disorder).

This research has several methodological strengths. We conducted two experiments, which allowed us to replicate and extend our key findings. We also used a multi-method assessment approach, thus circumventing subjectivity and mono-method biases. The CBM procedure we used was unobtrusive and relatively time- and cost-efficient. And lastly, we sampled, for the first time in this literature, boys referred for aggressive behavior problems - those who are in particular need of intervention (De Castro et al. 2002).

Future work may consider the school context when examining the effectiveness of the procedure. Children's aggression levels differ between schools-as such, it will be valuable to consider classroom and school system characteristics (Alexander 2001). For example, future work may assess classroom sociometrics, or real-time peer and teacher interactions (e.g. Hudley et al. 2007). Similarly, future work may assess aggression as it occurs outside of the school context (e.g., at home), and identify contextual factors influencing the effectiveness of the training. For example, strict classroom management and teacher-control might overrule any effects of the training, simply because there are less situations in class in which a child can behave aggressively. In less structured contexts outside the school, however, training effects may be more likely to be found.

Second, future work may seek to more comprehensively target other implicit processes that are known to contribute to children's aggressive behaviour. For example, aggressive children high on psychopathic traits show deficits in the processing of fearful facial expressions (Blair 1999; Frick et al. 2003). These children might benefit from a CBM procedure to target this deficit (Dadds et al. 2006). A procedure targeting both hostile attributions and deficits in fear recognition in this clinical group might be especially promising.

Third, longitudinal research should examine the longterm effects of this procedure. It is possible that it produces sleeper effects; that its long-term effects are larger than its immediate effects. Indeed, social information processing theory (Crick and Dodge 1994) predicts that interventions are effective to the extent that they modify recursive processes that unfold over time (Yeager and Walton 2011). To strengthen such recursive processes, it may be interesting to test additional effects of this training as an add-on to evidence-based interventions, such as parent training or classroom management. It is possible that CBM procedures, such as the one we used, may help amplify the putative effects of such interventions that target the family or school context. 
Overall, our research shows promising results; the CBM procedure that we used effectively reduced aggressive boys' hostile attributions. The training is time- and cost-efficient, and relatively easily implemented. However, we found no generalization in terms of children's emotion (i.e., anger) and behavior (i.e., aggression). We conclude that the training is not yet ready to be implemented as an intervention on a larger scale, but its potential deserves further empirical scrutiny.

\section{Compliance with Ethical Standards}

Conflict of Interest Wieteke Hiemstra, Bram Orobio De Castro, and Sander Thomaes declare that they have no conflict of interest.

Ethical Approval All procedures performed in studies involving human participants were in accordance with the ethical standards of the institutional and/or national research committee and with the 1964 Helsinki declaration and its later amendments or comparable ethical standards.

Informed Consent Informed consent was obtained from all individual participants included in the study.

Human and Animal Rights All the procedures followed were in accordance with the ethical standards of the responsible committee on human experimentation (institutional and national).

Open Access This article is distributed under the terms of the Creative Commons Attribution 4.0 International License (http://creativeco mmons.org/licenses/by/4.0/), which permits unrestricted use, distribution, and reproduction in any medium, provided you give appropriate credit to the original author(s) and the source, provide a link to the Creative Commons license, and indicate if changes were made.

\section{References}

Alexander, R. J. (2001). Border crossings: Towards a comparative pedagogy. Comparative Education, 37(4), 507-523.

Anderson, C. A., \& Bushman, B. J. (2002). Human aggression. Annual Review of Psychology, 53, 27-51.

Blair, R. J. R. (1999). Responsiveness to distress cues in the child with psychopathic tendencies. Personality and Individual Differences, 27(1), 135-145.

Card, N. A., Stucky, B. D., Sawalani, G. M., \& Little, T. D. (2008). Direct and indirect aggression during childhood and adolescence: A meta-analytic review of gender differences, intercorrelations, and relations to maladjustment. Child Development, 79(5), $1185-1229$.

Cohen, J. (1988). Statistical power analysis for the behavioral sciences (2nd ed.). NY: Routledge Academic.

Crick, N. R., \& Dodge, K. A. (1994). A review and reformulation of social information- processing mechanisms in children's social adjustment. Psychological Bulletin, 115(1), 74-101.

Crick, N. R., \& Dodge, K. A. (1996). Social information-processing mechanisms in reactive and proactive aggression. Child Development, 67(3), 993-1002.

Cristea, I. A., Mogoase, C., David, D., \& Cuijpers, P. (2015). Practitioner review: Cognitive bias modification for mental health problems in children and adolescents: A meta- analysis. Journal of Child Psychology \& Psychiatry, 56(7), 723-734.

Dadds, M. R., Perry, Y., Hawes, D. K., Merz, S., Riddell, A. C., Haines, D. J., ... Abeygunawardane, A. I. (2006). Attention to the eyes and fear-recognition deficits in child psychopathy. The British Journal of Psychiatry, 189(3), 280-281.

De Castro, B., Veerman, J. W., Koops, W., Bosch, J. P., \& Monshouwer, H. J. (2002). Attribution of intent and aggressive behavior: A meta-analysis. Child Development, 73(3), 916-934.

Del Barrio, V., Aluja, A., \& Spielberger, C. (2004). Anger assessment with the STAXI-CA: Psychometric properties of a new instrument for children and adolescents. Personality and Individual Differences, 37(2), 227-244.

Dishion, T. J., French, D. C., \& Patterson, G. R. (1995). The development and ecology of antisocial behavior. In D. Cicchetti \& D. J. Cohen (Eds.), Developmental psychopathology. Vol. 2: Risk, disorder, and adaptation (pp. 421-471). New York: Wiley.

Dodge, K. A. (2006). Translational science in action: Hostile attributional style and the development of aggressive behavior problems. Development and Psychopathology, 18(3), 791-814.

Dodge, K. A., Malone, P. S., Lansford, J. E., Sorbring, E., Skinner, A. T., Tapanya, S., ... Bacchini, D. (2015). Hostile attributional bias and aggressive behavior in global context. Proceedings of the National Academy of Sciences, 112(30), 9310-9315.

Dodge, K. A., Price, J. M., Bachorowski, J.-A., \& Newman, J. P. (1990). Hostile attributional biases in severely aggressive adolescents. Journal of Abnormal Psychology, 99(4), 385-392.

Eisenberg, N., Sadovsky, A., Spinrad, T. L., Fabes, R. A., Losoya, S. H., Valiente, C., ... Shepard, S. A. (2005). The relations of problem behavior status to children's negative emotionality, effortful control, and impulsivity: Concurrent relations and prediction of change. Developmental Psychology, 41(1), 193-211.

Ekman, P. (1993). Facial expression and emotion. American Psychologist, 48(4), 384-392.

Elias, M. J. (2004). The connection between social-emotional learning and learning disabilities: Implications for intervention. Learning Disability Quarterly, 27(1), 53-63.

Etcoff, N. L., \& Magee, J. J. (1992). Categorical perception of facial expressions. Cognition, 44(3), 227-240.

Fairchild, G., Van Goozen, S. H. M., Calder, A. J., Stollery, S. J., \& Goodyer, I. A. (2009). Deficits in facial expression recognition in male adolescents with early-onset of adolescence-onset conduct disorder. The Journal of Child Psychology and Psychiatry, 50(5), 627-636.

Fergusson, D. M., Horwood, J. L., \& Ridder, E. M. (2005). Show me the child at seven: The consequences of conduct problems in childhood for psychosocial functioning in adulthood. Journal of Child Psychology and Psychiatry, 46(8), 837-849.

Frick, P. J., Cornell, A. H., Barry, C. T., Bodin, S. D., \& Dane, H. E. (2003). Callous-unemotional traits and conduct problems in the prediction of conduct problem severity, aggression, and self-report of delinquency. Journal of Abnormal Child Psychology, 31(4), $457-470$.

Guerra, N. G., \& Slaby, R. G. (1990). Cognitive mediators of aggression in adolescent offenders: 2. Intervention. Developmental Psychology, 26(2), 269-277.

Hallion, L. S., \& Ruscio, A. M. (2011). A meta-analysis of the effect of cognitive bias modification on anxiety and depression. Psychological Bulletin, 137(6), 940-958.

Hendriks, M. C. P., \& Vingerhoets, J. J. M. (2006). Social messages of crying faces: Their influence on anticipated person perception, emotions and behavioural responses. Cognition and Emotion, 20(6), 878-886

Henry, J. D., Moses, E., Castellini, J., \& Scott, J. (2015). Mental health problems in adolescence and the interpretation of unambiguous threat. PLOS ONE, 10(6), e0127167. 
Hertel, P. T., \& Mathews, A. (2011). Cognitive bias modification past perspectives, current findings, and future applications. Perspectives on Psychological Science, 6(6), 521-536.

Hudley, C., \& Graham, S. (1993). An attributional intervention to reduce peer-directed aggression among African-American boys. Child Development, 64(1), 124-138.

Hudley, C., Graham, S., \& Taylor, A. (2007). Reducing aggressive Behavior and increasing motivation in school: The evolution of an intervention to strengthen school adjustment. Educational Psychologist, 42(4), 251-260.

Hurley, J. C., \& Underwood, M. K. (2002). Children's understanding of their research rights before and after debriefing: Informed assent, confidentiality, and stopped participation. Child Development, 73(1), 132-144.

Krebs, G., Pile, V., Grant, S., Degli Esposti, M., Montgomery, P., \& Lau, J. Y. (2017). Research Review: Cognitive bias modification of interpretations in youth and its effect on anxiety: A meta-analysis. Journal of Child Psychology and Psychiatry, 59(8), 831-844.

Landis, J. R., \& Koch, G. G. (1977). The measurement of observer agreement for categorical data. Biometrics, 33(1), 159-174.

Lochman, J. E., \& Wells, K. C. (2002). Contextual social-cognitive mediators and child outcome: A test of the theoretical model in the Coping Power program. Development and Psychopathology, 14(4), 945-967.

MacLeod, C., Koster, E. H. W., \& Fox, E. (2009). Whither cognitive bias modification research? Commentary on the special section articles. Journal of Abnormal Psychology, 118(1), 89-99.

MacLeod, C., \& Mathews, A. (2012). Cognitive bias modification approaches to anxiety. Annual Review of Clinical Psychology, 8, 189-217.

Mathôt, S., Schreij, D., \& Theeuwes, J. (2012). OpenSesame: An open-source, graphical experiment builder for the social sciences. Behavior Research Methods, 44(2), 314-324.

Mellentin, A. I., Dervisevic, A., Stenager, E., Pilegaard, M., \& Kirk, U. (2015). Seeing enemies? A systematic review of anger bias in the perception of facial expressions among anger-prone and aggressive populations. Aggression and Violent Behavior, 25, 373-383.

Monteith, M. J., Sherman, J. W., \& Devine, P. G. (1998). Suppression as a stereotype control strategy. Personality and Social Psychology, 2(1), 63-82.

Nasby, W., Hayden, B., \& DePaulo, B. M. (1980). Attributional bias among aggressive boys to interpret unambiguous social stimuli as displays of hostility. Journal of Abnormal Psychology, 89(3), 459-468.

Nix, R. L., Pinderhughes, E. E., Dodge, K. A., Bates, J. E., Pettit, G. S., \& McFadyen-Ketchum, S. A. (1999). The relation between mothers' hostile attribution tendencies and children's externalizing behavior problems: The mediating role of mothers' harsh discipline practices. Child Development, 70(4), 896-909.

Penton-Voak, I. S., Munafò, I. S., \& Yen Looi, C. (2017). Biased facialexpression perception in mental health disorders: A possible target for psychological intervention? Current Directions in Psychological Science, 26(3), 294-301.

Penton-Voak, I. S., Thomas, J., Gage, S. H., McMurran, M., McDonald, S., \& Munafò, M. R. (2013). Increasing recognition of happiness in ambiguous facial expressions reduces anger and aggressive behavior. Psychological Science, 24(5), 688-697.

Polman, H., de Castro, O., Thomaes, B. S., \& van Aken, M. (2009). New directions in measuring reactive and proactive aggression:
Validation of a teacher questionnaire. Journal of Abnormal Child Psychology, 37(2), 183-193.

Polman, H., Orobio de Castro, B., Koops, W., van Boxtel, H. W., \& Merk, W. W. (2007). A meta-analysis of the distinction between reactive and proactive aggression in children and adolescents. Journal of Abnormal Child Psychology, 35(4), 522-535.

Reijntjes, A., Thomaes, S., Bushman, B. J., Boelen, P. A., Orobio de Castro, B., \& Telch, M. J. (2010). The outcast-lash-out effect in youth: Alienation increases aggression following peer rejection. Psychological Science, 21(10), 1394-1398.

Salemink, E., \& Wiers, R. W. (2011). Modifying threat-related interpretive bias in adolescents. Journal of Abnormal Child Psychology, 39(7), 967-976.

Schönenberg, M., \& Justyte, A. (2014). Investigation of the hostile attribution bias toward ambiguous facial cues in antisocial violent offenders. European Archives of Psychiatry \& Clinical Neuroscience, 264(1), 61-69.

Spielberger, C. D. (1988). Manual for the State-Trait Anger Expression Inventory. Odessa: Psychological Assessment Resources.

Statistics Netherlands. (2014). 70 Thousand pupils in special education ("70 Duizend leerlingen in het special basisonderwijs"). Retrieved from https://www.cbs.nl/nl- nl/nieuws/2014/30/70-duizend-basis schoolleerlingen-in-speciaal-onderwijs.

Stoddard, J., Sharif-Askary, B., Harkins, E. A., Frank, H. R., Brotman, M. A., Penton-Voak, I. S., ... Leibenluft, E. (2016). An open pilot study of training hostile interpretation bias to treat disruptive mood dysregulation disorder. Journal of Child and Adolescent Psychopharmacology, 26(1), 49-57.

Sukhodolsky, D. G., Smith, S. D., McCauley, S. A., Ibrahim, K., \& Piasecka, J. B. (2016). Behavioral interventions for anger, irritability, and aggression in children and adolescents. Journal of Child and Adolescent Psychopharmacology, 26(1), 58-64.

Vassilopoulos, S. P., Brouzos, A., \& Andreou, E. (2015). A multi-session attribution modification program for children with aggressive behaviour: Changes in attributions, emotional reaction estimates, and self-reported aggression. Behavioural and Cognitive Psychotherapy, 43(5), 538-548.

Vlamings, P. H. J. M., Jonkman, L. M., \& Kemner, C. (2010). An eye for detail: An event- related potential study of the rapid processing of fearful facial expressions in children. Child Development, 81(4), 1304-1319.

Walker-Andrews, A. S. (1997). Infants' perception of expressive behaviors: Differentiation of multimodal information. Psychological Bulletin, 121(3), 437-456.

Wilkoswki, B. M., \& Robinson, M. D. (2008). The cognitive basis of trait anger and reactive aggression: An integrative analysis. Personality and Social Psychology Review, 12(1), 3-21.

Wilkowski, B. M., Crowe, S. E., \& Ferguson, E. L. (2015). Learning to keep your cool: Reducing aggression through the experimental modification of cognitive control. Cognition and Emotion, 29(2), 251-265.

Yeager, D. S., \& Walton, G. M. (2011). Social-psychological interventions in education: They're not magic. Review of Educational Research, 81(2), 267-301.

Young, A. W., Rowland, D., Calder, A. J., Etcoff, N. L., \& Perrett, D. I. (1997). Facial expression megamix: Tests of dimensional and category accounts of emotion recognition. Cognition, 63(3), 271-313. 